\title{
HC toxin (a HDAC inhibitor) enhances IRS1-Akt signalling and metabolism in mouse myotubes
}

\author{
Hayden Weng Siong Tan, Arthur Yi Loong Sim, Su Ling Huang', Ying Leng' \\ and Yun Chau Long
}

Department of Biochemistry, Yong Loo Lin School of Medicine, National University of Singapore, Block MD 7 , 8 Medical Drive, \#03-08, Singapore 117597, Singapore

${ }^{1}$ State Key Laboratory of Drug Research, Shanghai Institute of Materia Medica, Chinese Academy of Sciences, Shanghai 201203, China
Correspondence should be addressed to Y C Long

Email

bchlongy@nus.edu.sg

\begin{abstract}
Exercise enhances numerous signalling pathways and activates substrate metabolism in skeletal muscle. Small molecule compounds that activate these cellular responses have been shown to recapitulate the metabolic benefits of exercise. In this study, a histone deacetylase (HDAC) inhibitor, $\mathrm{HC}$ toxin, was investigated as a small molecule compound that activates exercise-induced adaptations. In C2C12 myotubes, HC toxin treatment activated two exercise-stimulated pathways: AMP-activated protein kinase (AMPK) and Akt pathways. $\mathrm{HC}$ toxin increased the protein content and phosphorylation of insulin receptor substrate 1 as well as the activation of downstream Akt signalling. The effects of HC toxin on IRS1-Akt signalling were PI3K-dependent as wortmannin abolishes its effects on IRS1 protein accumulation and Akt phosphorylation. $\mathrm{HC}$ toxin-induced Akt activation was sufficient to enhance downstream mTOR complex 1 (mTORC1) signalling including p70S6K and S6, which were consistently abolished by PI3K inhibition. Insulin-stimulated glucose uptake, glycolysis, mitochondrial respiration and fatty acid oxidation were also enhanced in HC toxin-treated myotubes. When myotubes were challenged with serum starvation for the induction of atrophy, $\mathrm{HC}$ toxin treatment prevented the induction of genes that are involved in autophagy and proteasomal proteolysis. Conversely, IRS1-Akt signalling was not induced by $\mathrm{HC}$ toxin in several hepatoma cell lines, providing evidence for a favourable safety profile of this small molecule. These data highlight the potential of HDAC inhibitors as a novel class of small molecules for the induction of exercise-like signalling pathways and metabolism.
\end{abstract}

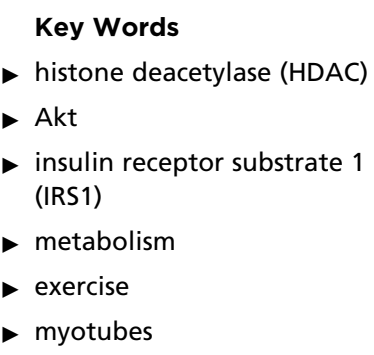

\section{Introduction}

Exercise plays a pivotal role in the prevention and treatment of metabolic diseases, including diabetes and obesity. Although exercise has a body-wide effect, it is believed that these benefits require metabolic adaptations in the skeletal muscle (Hawley 2004). Indeed, exercise enhances the utilisation and storage of metabolic substrates by skeletal muscle, which, in turn, prevent the detrimental accumulation of excess macronutrients in the circulation (Hawley 2004, Abdul-Ghani \& DeFronzo 2010). Although the molecular mechanisms underlying exercise-induced adaptations in muscle have not been fully elucidated, AMP-activated protein kinase (AMPK)

Published by Bioscientifica Ltd. 
and Akt have been proposed to play a role. Studies have shown that exercise activates Akt in mouse and human skeletal muscle (Sakamoto et al. 2003, Deshmukh et al. 2006), and the overexpression of constitutively active Akt in L6 myotubes stimulates glucose uptake in the absence of insulin (Hajduch et al. 1998). In contrast, pharmacological inhibition of Akt reduced contraction-stimulated glucose uptake in skeletal muscle cells (Wojtaszewski et al. 1996, Osorio-Fuentealba et al. 2013). Collectively, these studies suggest a role for Akt in exercise-induced glucose uptake.

Exercise promotes hypertrophy and prevents atrophy in skeletal muscle through the activation of mechanistic target of rapamycin complex 1 (mTORC1), a critical downstream target of Akt (Bodine et al. 2001). Inhibition of exercise-induced mTORC1 signalling by rapamycin blocked protein synthesis in both human and rodent skeletal muscle (Kubica et al. 2005, Drummond et al. 2009) and prevented muscle hypertrophy induced by overload or the overexpression of constitutively active Akt in mice (Bodine et al. 2001, Pallafacchina et al. 2002). Akt also inactivates Forkhead box Class $\mathrm{O}$ (FoxO) transcription factors, which induce muscle atrophy through the expression of numerous atrophy-related genes, including MuRF-1 and atrogin-1 (Zhao et al. 2007). The expression of dominant-negative FoxO in skeletal muscle prevented atrophy in cachectic mice and induced hypertrophy in normal mice (Reed et al. 2012). Conversely, the expression of a constitutively active mutant of FoxO3a induced atrophy in both $\mathrm{C} 2 \mathrm{C} 12$ myotubes and mouse skeletal muscle (Sandri et al. 2004). Thus, exercise promotes muscle hypertrophy and suppresses atrophy through a coordinated change in the Akt-regulated anabolic and catabolic mediators, mTORC1 and FoxO, respectively.

AMPK is an energy-sensing molecule that is activated during periods of energetic stress and has been identified as a key signalling molecule in exercise (Richter \& Ruderman 2009). Numerous studies have demonstrated that pharmacological activation of AMPK produces metabolic responses and adaptations that are similar to those observed in exercise. Chronic administration of the AMPK activator, AICAR, improved skeletal muscle insulin sensitivity and prevented the development of hyperglycaemia in a diabetic rat model; these effects were similar to that observed in response to long-term exercise training (Pold et al. 2005). Similarly, both exercise and chronic AICAR treatment enhanced the expression of genes involved in lipid utilisation and insulin-stimulated glucose uptake in rat muscle (Jessen et al. 2003). Further evidence for the role of AMPK in exercise-induced effects comes from genetic mouse models. The expression of kinase-dead AMPK in mouse skeletal muscle impaired contraction-stimulated glucose uptake (Mu et al. 2001), whereas knockout of the AMPK $\gamma 3$ subunit accelerated muscle fatigue and impaired transcriptional adaptations in response to exercise (Barnes et al. 2005). Thus, AMPK activation is a hallmark of exercise-induced signalling and could be used to recapitulate the beneficial effects of exercise.

Histone deacetylases (HDACs) are enzymes that catalyse the removal of acetyl groups from histones, which result in chromatin compaction and subsequent repression of gene expression (De Ruijter et al. 2003). Recent studies suggest that HDACs play a role in the regulation of skeletal muscle metabolism. Dietary supplementation of butyrate prevented diet-induced insulin resistance in mice, and this effect was associated with an inhibition of HDAC (Gao et al. 2009). In addition, it was recently shown that knockdown of HDAC5 in human muscle cells resulted in increased glucose uptake and insulin-stimulated glycogen synthesis (Raichur et al. 2012). This raises the possibility that HDAC inhibitors may be used to modulate exercise-induced signalling and adaptations in skeletal muscle.

In this study, we evaluated the potential of Helminthosporium carbonum (HC) toxin, a previously established HDAC inhibitor, as a small molecule that induces exercise-like adaptations in skeletal muscle. HC toxin is a cyclic tetrapeptide originally identified as a host-selective toxin from the maize pathogenic fungus Cochliobolus (Helminthosporium) carbonum (Mottamal et al. 2015), and it was shown to inhibit class I HDAC enzymes (HDAC1, -2, -3 and -8) in mammalian cells (Brosch et al. 1995, Hildmann et al. 2006). Herein, we report that HC toxin activates two exercise-activated pathways in C2C12 myotubes: AMPK and Akt pathways. These changes are associated with metabolic gene reprogramming as well as enhanced glucose and lipid metabolism. We also show that HC toxin treatment activates mTORC1 and suppresses atrophy-related genes in myotubes, an effect that is observed less in other reported exercise mimetics. These data highlight the potential of HDAC inhibitors as a novel class of small molecules for the induction of an exerciselike signalling and metabolic program.

\section{Materials and methods}

\section{Materials}

Antibodies against phospho-AMPK $\alpha$ (Thr172), AMPK $\alpha$, phospho-Akt (Ser473), Akt, PDK1, phospho-p70S6K

Published by Bioscientifica Ltd. 
(Thr389), p70S6K, phospho-S6 (Ser235/236), S6, phosphoIRS1 (Ser318), phospho-IRS1 (Ser612), IRS1, IRS2, phospho-FoxO3a (Ser253), FoxO3a and HRP-linked secondary anti-rabbit antibodies were from Cell Signaling Technology (Beverly, MA, USA). HC toxin was from Cayman Chemical (Ann Arbor, MI, USA). Wortmannin, dimethylsulfoxide, oligomycin, carbonyl cyanide-4-(trifluoromethoxy) phenylhydrazone (FCCP), antimycin A, rotenone, sodium palmitate and real-time PCR primers were from Sigma-Aldrich (St Louis, MO, USA).

\section{Cell culture}

Mouse C2C12 myoblasts, human HepG2 hepatoma cells, rat H4IIE hepatoma cells (ATCC, Manassas, VA, USA), human Huh7 and Huh6 hepatoma cells (JCRB Cell Bank, Osaka, Japan) were maintained in DMEM (SH30249; GE Healthcare Life Sciences HyClone Laboratories, Logan, UT, USA) supplemented with $10 \%$ fetal bovine serum (FBS), $100 \mathrm{U} / \mathrm{ml}$ penicillin, $100 \mu \mathrm{g} / \mathrm{ml}$ streptomycin and $1 \mathrm{mM}$ sodium pyruvate. The cells used were $<20$ passages. For C2C12 myoblasts, media was switched to differentiation media (DMEM supplemented with $2 \%$ horse serum, $100 \mathrm{U} / \mathrm{ml}$ penicillin, $100 \mu \mathrm{g} / \mathrm{ml}$ streptomycin and $1 \mathrm{mM}$ sodium pyruvate) over 3 days to initiate the differentiation of myoblasts to myotubes. C2C12 myotubes in differentiation media and hepatoma cells in serum-free media (supplemented with $0.2 \% \mathrm{BSA}$ ) were treated with $\mathrm{HC}$ toxin at the times and concentrations indicated. For PI3K inhibition experiments, $200 \mathrm{nM}$ wortmannin was added during the last $2 \mathrm{~h}$ of the $\mathrm{HC}$ toxin treatment.

\section{Immunoblotting}

Cells were homogenized on ice in $0.2 \mathrm{ml}$ of ice-cold lysis buffer containing $25 \mathrm{mM}$ Tris- $\mathrm{HCl}$ (pH 7.4), $150 \mathrm{mM} \mathrm{NaCl}$, 1\% IGEPAL, $24 \mathrm{mM}$ sodium deoxycholate, $0.1 \%$ SDS, $5 \mathrm{mM}$-glycerophosphate, $5 \mathrm{mM} \mathrm{NaF}, 5 \mathrm{mM} \mathrm{Na}_{3} \mathrm{VO}_{4}$ and $1 \%$ Halt protease inhibitor cocktail (Life Technologies, Carlsbad, CA, USA). Lysates were subjected to brief sonication and centrifuged at $13000 \boldsymbol{g}$ for $10 \mathrm{~min}$ to remove insoluble cell debris, and the supernatant was diluted in Laemmli sample buffer. Proteins $(30 \mu \mathrm{g} /$ well $)$ were separated by SDS-PAGE and transferred to PVDF membranes (Bio-Rad Laboratories). Membranes were blocked with $5 \%$ non-fat milk, incubated overnight with primary antibodies, washed and then incubated with secondary antibodies. Proteins were visualized by chemiluminescence and quantified by densitometry using ImageJ (NIH, Bethesda, MD, USA).

\section{Quantitative real-time PCR}

Total RNA was extracted from myotubes using the ReliaPrep RNA Cell Miniprep System (Promega) following the manufacturer's protocol. cDNA was prepared using SuperScript III First-Strand Synthesis System for RT-PCR (Life Technologies). Quantitative real-time PCR (qRT-PCR) reaction consisted of $1 \times$ SYBR Select Master Mix (Life Technologies), $10 \mu \mathrm{M}$ each of gene-specific forward and reverse primers and $30 \mathrm{ng}$ cDNA per reaction. qRT-PCR was performed in a 96-well plate format, and reactions were carried out on the Applied Biosystems 7300 RealTime PCR System. The abundance of target gene mRNA was normalized to housekeeping genes $36 \mathrm{~B} 4$ or $\beta$-actin.

\section{Glucose uptake assay}

C2C12 myotubes were incubated with or without HC toxin in DMEM supplemented with $2 \%$ horse serum for $24 \mathrm{~h}$. Myotubes were then washed with warm PBS and subsequently incubated in KRHB $(130 \mathrm{mM} \mathrm{NaCl}, 5 \mathrm{mM}$ $\mathrm{KCl}, 1.3 \mathrm{mM} \mathrm{MgSO}_{4}, 1.3 \mathrm{mM} \mathrm{CaCl} 2,25 \mathrm{mM}$ HEPES, $\mathrm{pH}$ 7.4) with or without insulin for $20 \mathrm{~min}$, followed by incubation with $0.05 \mathrm{mM}$ 2-deoxy-D-glucose and $1.85 \times$ $10^{4} \mathrm{~Bq} / \mathrm{ml} 2$-deoxy-D-[1,2- $\left.{ }^{3} \mathrm{H}\right]$ glucose for $10 \mathrm{~min}$. Radioactivity was determined by liquid scintillation counting (Perkin Elmer Trilu, Waltham, MA, USA).

\section{Measurements of extracellular acidification rate and oxygen consumption rate}

C2C12 myoblasts were plated and differentiated on XF24 cell culture microplates. Myotubes were then treated with $\mathrm{HC}$ toxin at the times and concentrations as indicated. Media was then switched to unbuffered DMEM (D5030; Sigma-Aldrich) supplemented with $25 \mathrm{mM}$ glucose, $4 \mathrm{mM}$ glutamine and $2 \%$ horse serum. For extracellular acidification rate (ECAR) experiments, $1 \mathrm{mM}$ sodium pyruvate was added. Myotubes were subsequently incubated in a non$\mathrm{CO}_{2}$ incubator for $1 \mathrm{~h}$. ECAR and oxygen consumption rate (OCR) measurements were then performed using the $\mathrm{XF}^{\mathrm{e}} 24$ flux analyser (Seahorse Bioscience, North Billerica, MA, USA). During ECAR measurements, $1 \mu \mathrm{M}$ oligomycin, $0.7 \mu \mathrm{M}$ carbonyl cyanide-p-trifluoromethoxyphenylhydrazone (FCCP) and $1 \mu \mathrm{M}$ antimycin A/rotenone were sequentially added. Each cycle consisted of $3 \mathrm{~min}$ of mixing, 2 min of pre-incubation and $3 \mathrm{~min}$ of measurement. For the measurement of fatty acid oxidation (FAO), the XF FAO assay was performed following manufacturer's instructions. Briefly, treated myotubes were switched to

Published by Bioscientifica Ltd 
KHB buffer $\left(111 \mathrm{mM} \mathrm{NaCl}, 4.7 \mathrm{mM} \mathrm{KCl}, 1.25 \mathrm{mM} \mathrm{CaCl}_{2}\right.$, $2 \mathrm{mM} \mathrm{MgSO}_{4}, 1.2 \mathrm{mM} \mathrm{NaH} \mathrm{PO}_{4}$ ) supplemented with $2.5 \mathrm{mM}$ glucose, $0.5 \mathrm{mM}$ carnitine, $25 \mathrm{mM}$ HEPES and $2 \%$ horse serum for $1 \mathrm{~h}$ in a non- $\mathrm{CO}_{2}$ incubator. OCR measurements were then performed. FAO was calculated as the difference between basal OCR and OCR after injection of $200 \mu \mathrm{M}$ palmitate conjugated to BSA.

\section{Results}

\section{HC toxin treatment induces AMPK and Akt-mTORC1 signalling in a dose-dependent manner}

The AMPK and Akt signalling pathways are two major signalling networks that are involved in exercise-mediated skeletal muscle adaptations. To evaluate the effect of HC toxin on AMPK and Akt signalling in skeletal muscle, C2C12 myotubes were treated with 0, 10, 30 and $100 \mathrm{nM}$ $\mathrm{HC}$ toxin for $48 \mathrm{~h}$. We found that HC toxin treatment increased p-AMPK (T172) and p-Akt (S473) in a dosedependent manner (Fig. 1A and B). Consistent with the activation of Akt, downstream mTOR signalling, as assessed by pS6 (S235/236), was also enhanced at the concentration of $100 \mathrm{nM}$ (Fig. 1C). The upstream signalling component of insulin/Akt signalling, IRS1, was also increased in a dose-dependent manner (Fig. 1D).

\section{HC toxin-induced IRS1-Akt signalling requires intact PI3K activity}

IRS1 plays a critical role in insulin-like signalling and it is involved in the enhancement of insulin sensitivity after exercise (Henriksen 2002). Given that HC toxin led to a robust increase in IRS1 protein, we further assessed changes in the IRS1 signalling pathway in response to $\mathrm{HC}$ toxin. We found that treatment with $\mathrm{HC}$ toxin resulted in increased p-IRS1 levels at S318 and S612, suggesting that both IRS1 phosphorylation and total protein levels are enhanced in response to $\mathrm{HC}$ toxin (Fig. 2A). Inhibition of PI3K/Akt by wortmannin caused a depletion in IRS1 protein levels and hampered the effects of HC toxin on the accumulation of the adaptor protein. As expected, wortmannin treatment reduced basal levels of S318 and S612 phosphorylation. However, $\mathrm{HC}$ toxin treatment was able to restore the phosphorylation of these PI3K-sensitive serine residues (Fig. 2A). Because IRS2 has also been identified as a mediator of insulin signalling, we assessed changes in the IRS2 pathway but found that $\mathrm{HC}$ toxin treatment did not alter IRS2 protein levels (Fig. 2A).

We next sought to determine whether other components in the insulin-like signalling pathway were affected by $\mathrm{HC}$ toxin treatment. Indeed, we found that HC toxin increased PDK1 (Fig. 2B), which initiates the activation of Akt (Manning \& Cantley 2007). Consistently, we observed an increase in the phosphorylation of Akt at S473 (Fig. 2C), which is required for its full activation. Wortmannin treatment abolished p-Akt (S473) (Fig. 2C) in the presence or absence of $\mathrm{HC}$ toxin, indicating that $\mathrm{HC}$ toxin-induced Akt activation is PI3K dependent. HC toxin also significantly increased the phosphorylation of the mTORC1 substrate p70S6K (T389) and its direct substrate S6 (S235/236), and, again, these effects were abolished by wortmannin and unable to be recovered by HC toxin (Fig. 2D and E), suggesting that the HC toxin-mediated mTORC1 signalling axis is PI3K-dependent.
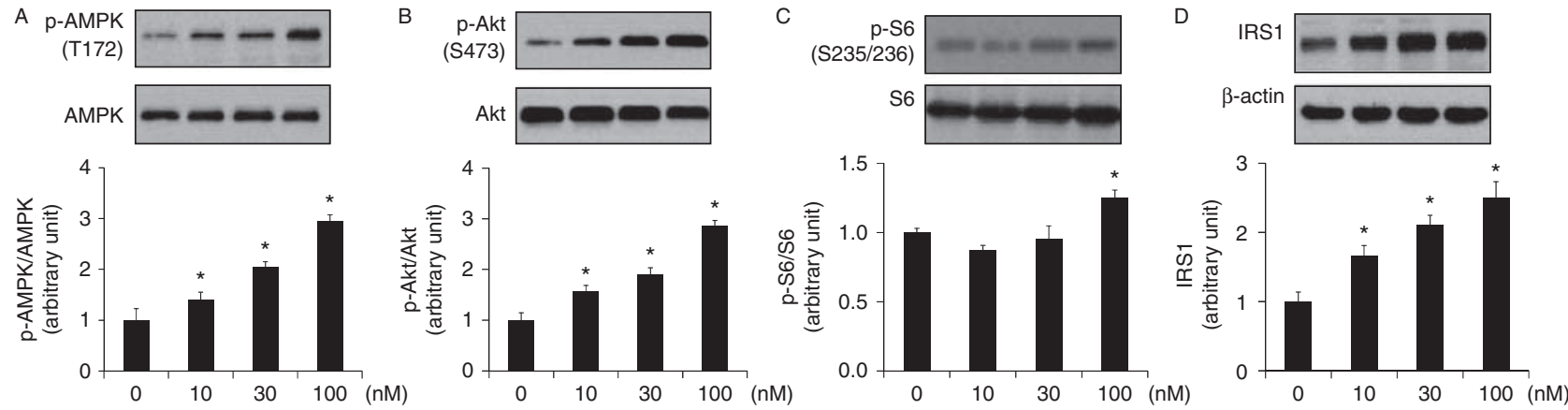

Figure 1

$\mathrm{HC}$ toxin enhances Akt and AMP-activated protein kinase (AMPK) signalling in $\mathrm{C} 2 \mathrm{C} 12$ myotubes. $\mathrm{C} 2 \mathrm{C} 12$ myotubes were incubated with $\mathrm{HC}$ toxin at various concentrations $(0,10,30$ and $100 \mathrm{nM})$ for $48 \mathrm{~h}$. Changes in the levels of p-AMPK (A), p-AKT (B), p-S6 (C) and total insulin receptor

substrate 1 (IRS1; D) were assessed by western blot. Representative blots and quantification are presented. Bars indicate the mean \pm S.E.M. ${ }^{\star} P<0.05$ vs the control group; $n=3$.

Published by Bioscientifica Ltd. 


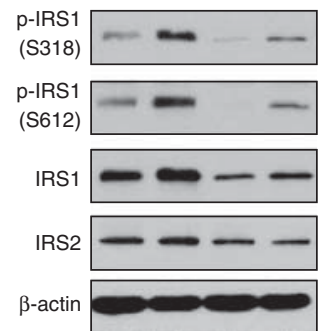

B

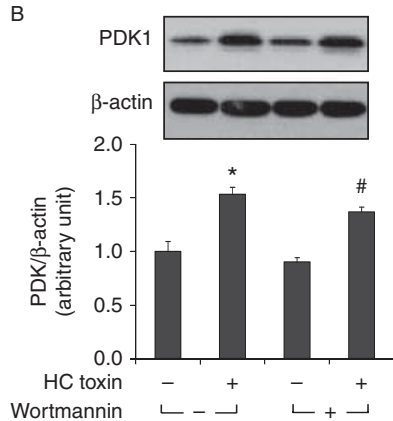

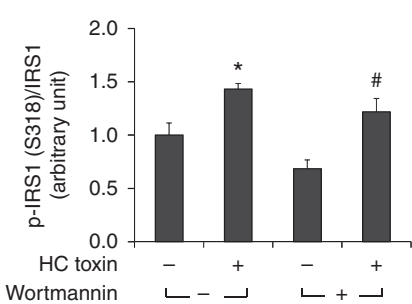

C

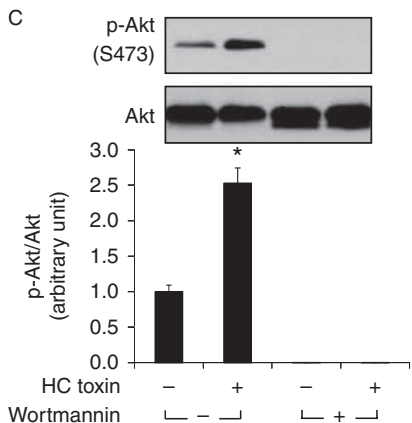

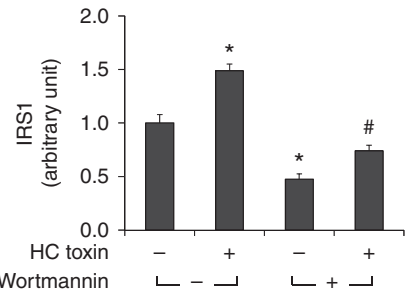

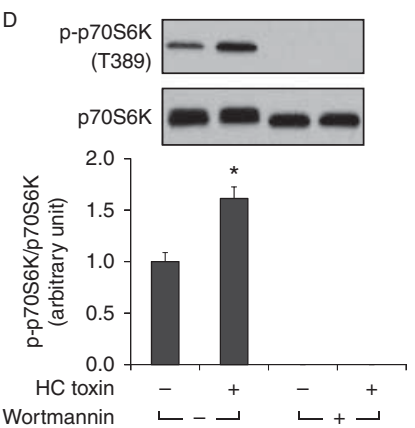

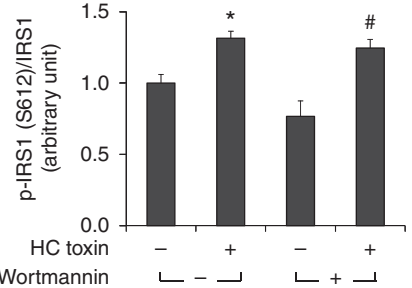

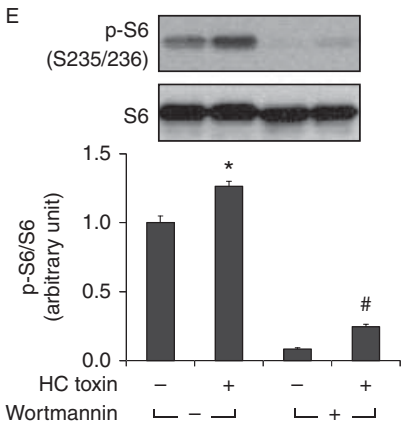

Figure 2

$\mathrm{HC}$ toxin-induced IRS1-Akt signalling requires intact PI3K activity. $\mathrm{C} 2 \mathrm{C} 12$ myotubes were treated with $\mathrm{HC}$ toxin $(100 \mathrm{nM})$ for $48 \mathrm{~h}$ in the presence or absence of wortmannin (200 nM) for the final $2 \mathrm{~h}$. Phosphorylation and protein levels of IRS1 and IRS2 (A), PDK1 (B), Akt (C), p70S6k (D) and S6 (E)

\section{$\mathrm{HC}$ toxin induces coordinated changes in the expression of metabolic genes}

Multiple studies have shown that a coordinated change of metabolic gene expression occurs in skeletal muscle after exercise to enhance fuel substrate metabolism (Mahoney et al. 2005). To investigate if HC toxin reprograms metabolic gene expression in $\mathrm{C} 2 \mathrm{C} 12$ myotubes, the mRNA levels of genes involved in glucose and lipid metabolism were assessed. Treatment with HC toxin increased the mRNA expression of glycolytic genes, $P k$ (82\%) and $L d h 2 b(77 \%)$, but reduced the expression of Pdk4 (38\%), a profile that is associated with enhanced glycolysis (Fig. 3). HC toxin also elevated the mRNA expression of $\mathrm{LPl}$ (159\%), Cpt1b (78\%), Slc25a20 (112\%), Had (87\%) and citrate synthase (Cs, 75\%), which are involved in lipid transport and metabolism. Consistently, the expression of the transcriptional coactivator $P g c 1 a$, which regulates mitochondrial biogenesis and respiration (Finck \& Kelly 2006), was increased (224\%).

\section{HC toxin modulates glucose uptake, cellular bioenergetics and FAO in myotubes}

We next assessed whether these changes in HC toxininduced cell signalling and gene expression are sufficient were assessed by western blot. Representative blots and quantification are presented. Bars indicate mean \pm S.E.M. ${ }^{*} P<0.05$ vs the control group; ${ }^{\#} P<0.05$ vs the wortmannin treated group; $n=6$.

to enhance glucose uptake. Myotubes were treated with $\mathrm{HC}$ toxin for $24 \mathrm{~h}$ to assess changes in glucose uptake. We found that HC toxin induced glucose uptake in a dosedependent manner, with a maximal effect seen at $30 \mathrm{nM}$ (Fig. 4A; white bars). Furthermore, stimulation with insulin had an additive effect, further increasing the rates of glucose uptake (Fig. 4A; grey bars). Consistent with the elevation of glucose uptake, HC toxin treatment increased basal and oligomycin-stimulated ECAR, suggesting an upregulation in glycolytic flux in response to the treatment (Fig. 4B). HC toxin treatment also increased basal OCR (50 and $100 \mathrm{nM}$ for 24 or $48 \mathrm{~h}$ ), providing evidence for an upregulation of mitochondrial respiration (Fig. 4C). In addition to an enhancement of glucose metabolism, HC toxin enhanced lipid metabolism. HC toxin $(10 \mu \mathrm{M})$ treatment elevated FAO in a timedependent manner (Fig. 4D).

\section{HC toxin-induced Akt activation is associated with the suppression of atrophy-related genes during nutrient deprivation}

In addition to mTORC1, Akt can regulate FoxO transcription factors via direct phosphorylation (Manning \& Cantley 2007). We found that HC toxin increased

Published by Bioscientifica Ltd. 


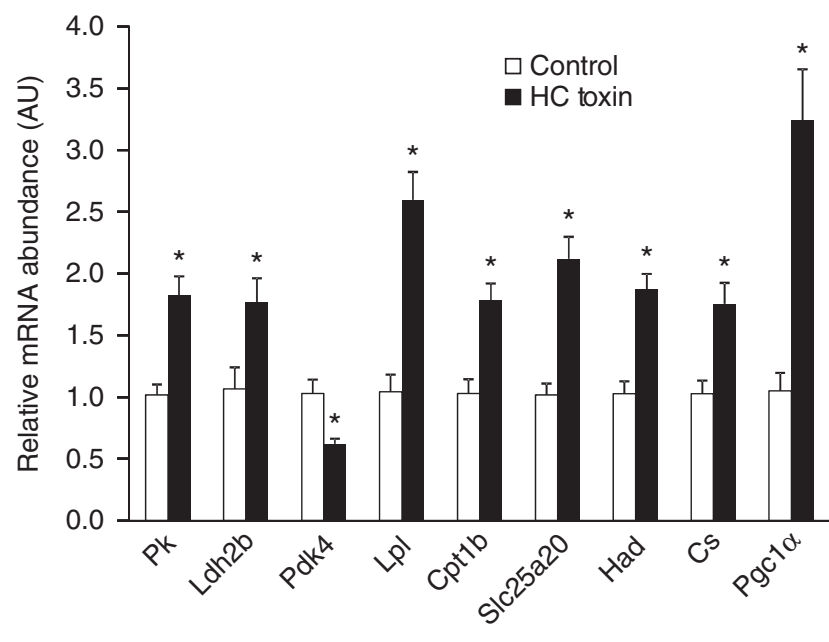

Figure 3

$\mathrm{HC}$ toxin induces coordinated expression of metabolic genes. $\mathrm{C} 2 \mathrm{C} 12$ myotubes were treated with $\mathrm{HC}$ toxin $(100 \mathrm{nM})$ for $48 \mathrm{~h}$. qPCR analysis of glycolytic genes: pyruvate kinase $(P k)$, lactate dehydrogenase $2 \mathrm{~b}(L d h 2 b)$ and pyruvate dehydrogenase kinase $4(P d k 4)$; lipid metabolic genes: carnitine palmitoyltransferase $1 \mathrm{~b}$ (Cpt1b), carnitine/acylcarnitine translocase (S/c25a20), lipoprotein lipase ( $L p l)$, 3-hydroxyacyl-CoA dehydrogenase $(\mathrm{Had})$ and citrate synthase (CS) and peroxisome proliferator-activated receptor gamma coactivator 1a (Pgc1a). Bars indicate mean \pm s.E.M. $* P<0.05$ vs the control group; $n=6$.

p-FoxO3a (S253) in myotubes, consistent with the increase in p-Akt (S473) (Fig. 5A). The effects of HC toxin on Akt and FoxO phosphorylation were retained even under serum-starved conditions (Fig. 5A). Given that FoxO transcription factors mediate the expression of multiple muscle atrophy-related genes (also known as atrogenes) (Zhao et al. 2007), we next assessed whether HC toxininduced FoxO3a phosphorylation is associated with the suppression of these genes. We found that $\mathrm{HC}$ toxin suppressed the expression of autophagy-related genes Atg5, Ulk2, Bnip3, Bnip3L, Gabarapl1, Lamp2a and Vps34 (Fig. 5B and C), as well as muscle-specific E3 ubiquitin ligases, MuRF1 and atrogin-1 (Fig. 5D), which are involved in proteasomal proteolysis. We next tested whether this effect could be sustained under serum-starved conditions, as this is routinely used to induce atrophy and atrogene expression in myotubes. Despite the absence of growth factor and the reduced nutrient supply, HC toxin was still able to prevent the induction of these atrogenes under serum-starved conditions (Fig. 5B, C and D).

\section{Discussion}

Activation of AMPK signalling in human and rodent skeletal muscles is a hallmark of physical exercise (Richter \& Ruderman 2009). The activation of AMPK during periods of energy stress, such as exercise, induces glucose uptake and lipid oxidation to restore the skeletal muscle energy balance (Long \& Zierath 2006). Here, we show that HC toxin can activate AMPK signalling in cultured myotubes, which demonstrates its potential to induce exercise-like adaptations in skeletal muscle. In addition, we observed an enhancement of Akt phosphorylation in C2C12 myotubes in response to HC toxin, an adaptation commonly observed in skeletal muscle in response to exercise and in situ muscle contraction (Taniguchi et al. 2006). Other HDAC inhibitors, including trichostatin A (TSA), sodium valproate and butyrate, have been reported to activate Akt in human neuroblastoma cells (De Sarno et al. 2002), suggesting that numerous HDAC inhibitors may share a similar pharmacological capacity to increase Akt activity. However, the molecular mechanism underlying Akt activation by HDAC inhibitors was largely unknown, and thus, here we sought to characterize the effect of HC toxin on the upstream components of the Akt signalling pathway. We found that HC toxin increases IRS1 protein content (Fig. 2A), which is a critical upstream adaptor protein that regulates insulin sensitivity in both humans and rodents (Henriksen 2002). Previous studies have demonstrated that genetic ablation of IRS1 in skeletal muscle results in insulin resistance and impaired insulin-stimulated glucose uptake (Yamauchi et al. 1996). Given that insulin-resistant individuals present with significantly lower expression of skeletal muscle IRS1 (Kovacs et al. 2003), this HC toxin-induced signalling network is, conceivably, an attractive means to restore insulin signalling.

IRS1 is subjected to extensive post-translational modifications, and several serine phosphorylation sites modulate its function. We found that HC toxin increased S318 phosphorylation, an early phosphorylation event that potentiates insulin signalling (Weigert et al. 2008). The phosphorylation of S612, which is mediated by S6K in response to insulin stimulation (Shah \& Hunter 2006), was also intact in HC toxin-treated myotubes. Both of these phosphorylation events were PI3K-dependent, as wortmannin greatly diminished the activity. Downstream of IRS1, we found a consistent elevation in PDK1, which is responsible for the initial activating phosphorylation of Akt in HC toxin-treated myotubes (Manning \& Cantley 2007). We further showed that this elevation in Akt phosphorylation in treated myotubes is wortmanninsensitive (Fig. 2), supporting the notion that $\mathrm{HC}$ toxin increased IRS1-Akt signalling. Thus, HC toxin-enhanced IRS-Akt signalling involves the phosphorylation of these signalling components in a PI3K-dependent manner.

Published by Bioscientifica Ltd 


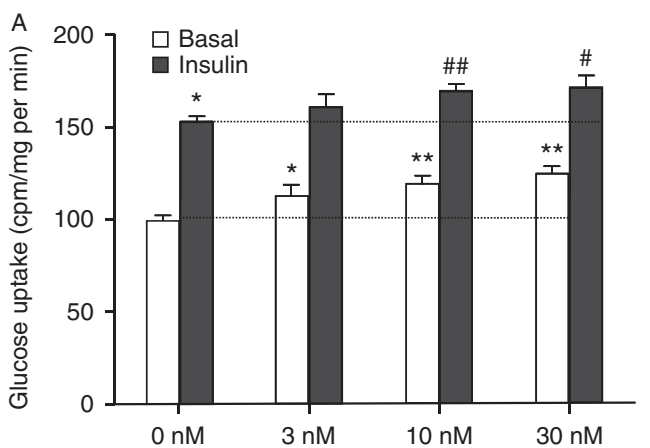

B
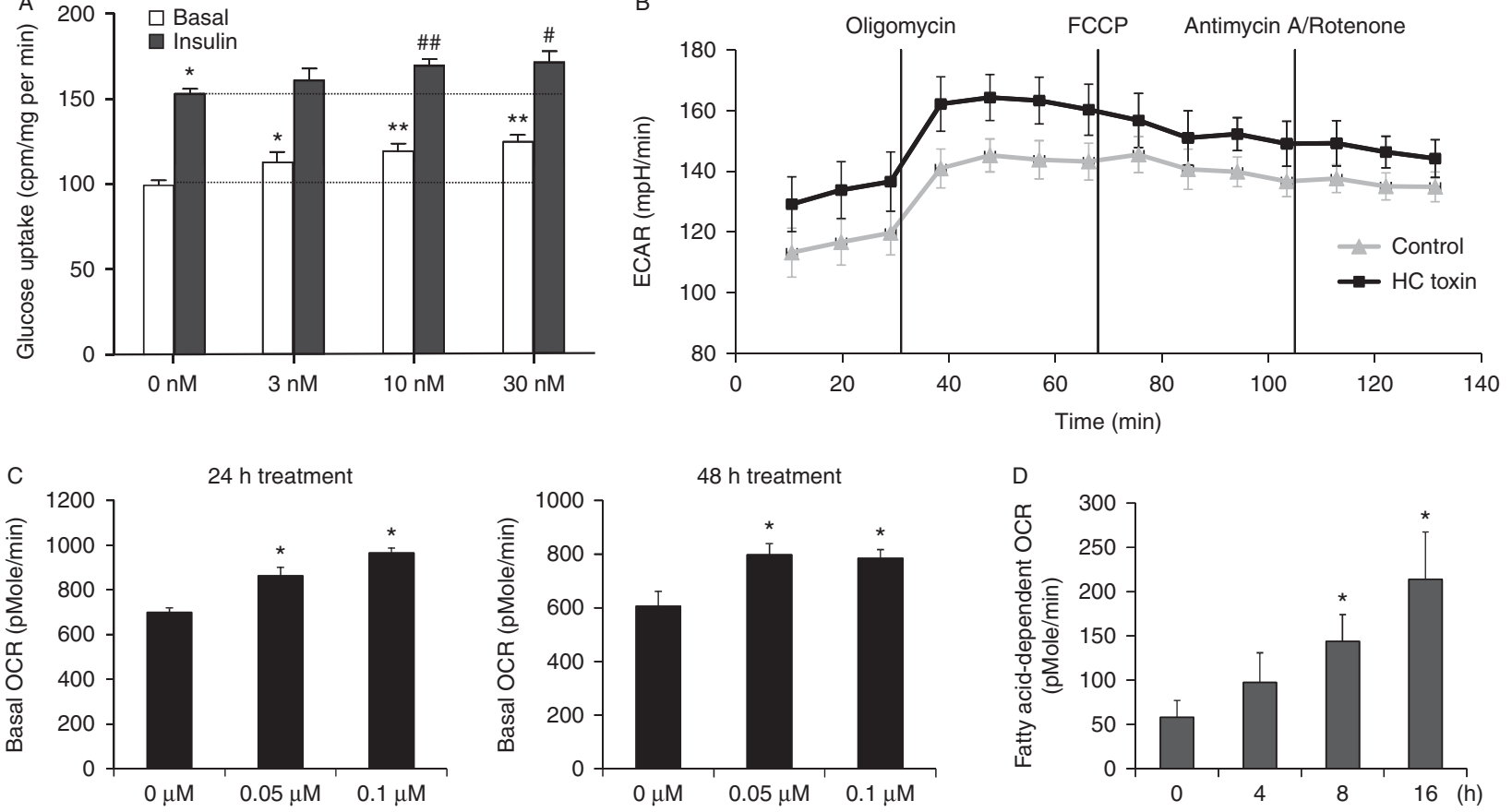

\section{Figure 4}

$\mathrm{HC}$ toxin enhances glucose uptake, glycolysis, mitochondrial respiration and fatty acid oxidation. (A) C2C12 myotubes were incubated with HC toxin for $24 \mathrm{~h}$, followed by insulin stimulation (100 $\mathrm{nM})$, and glucose uptake was assessed. ${ }^{*} P<0.05,{ }^{*} P<0.01$ vs the control group; ${ }^{\#} P<0.05$, ${ }^{\# \#} P<0.01$ vs the insulin-treated group. (B) ECARs were measured in control and HC toxin-treated $(50 \mathrm{nM}, 48 \mathrm{~h})$ myotubes. Oligomycin $(1 \mu \mathrm{M}), \mathrm{FCCP}(0.7 \mu \mathrm{M})$ and antimycin $(1 \mu \mathrm{M}) /$ rotenone $(1 \mu \mathrm{M})$ were sequentially added in the

The biological significance of HC toxin-induced IRS-Akt signalling is further supported by a corresponding increase in the phosphorylation of p70S6K and S6, two critical downstream targets of the Akt-mTORC1 axis.

Exercise is known to induce adaptations in cellular signalling and gene expression to enhance substrate metabolism in skeletal muscle (Mahoney et al. 2005, Egan \& Zierath 2013). Given that Akt plays a critical role in the regulation of glucose metabolism, we assessed whether the activation of Akt in HC toxin-treated myotubes altered the expression of certain metabolismrelated genes. We found that $\mathrm{HC}$ toxin increased the expression of $P k$ and $L d h 2 b$, whereas $P d k 4$ expression was reduced - an expression profile that is associated with enhanced glucose utilisation (Fig. 3) (Sugden \& Holness 2003). Consistently, HC toxin-treated myotubes displayed an enhanced basal as well as insulin-stimulated glucose uptake, concomitant with a higher rate of glycolysis, as indicated by ECAR (Fig. 4). Our results corroborate the findings of a previous study that showed that skeletal muscle-specific Akt1 transgene expression is sufficient to process. Error bars indicate S.E.M.; $n=3$. (C) Basal OCR was measured in control and HC toxin-treated myotubes ( 50 or $100 \mathrm{nM}$ for 24 or $48 \mathrm{~h}$ ). Bars indicate mean \pm S.E.M. ${ }^{*} P<0.05$ vs the control group; $n=5$. (D) $\mathrm{C} 2 \mathrm{C} 12$ myotubes incubated with $\mathrm{HC}$ toxin $(10 \mu \mathrm{M})$ for $0,4,8$ and $16 \mathrm{~h}$, and fatty acid oxidation was determined. Bars indicate mean \pm s.E.M. ${ }^{*} P<0.05$ vs the control group; $n=4-5$.

induce a glycolytic gene program and glucose metabolism in obese mice (Izumiya et al. 2008).

HC toxin also modulated the expression of genes involved in lipid metabolism. The expression of genes critical for the uptake $(L p l)$ and transport of lipid-derived fatty-acyl CoA into the mitochondria (Cpt1b and $S l c 25 a 20)$ were consistently elevated (Fig. 3). Had (a $\beta$-oxidation enzyme) and Cs (a TCA cycle enzyme) were also upregulated. Consistently, we observed an elevation in FAO in response to $\mathrm{HC}$ toxin treatment. HC toxin also upregulated the mRNA levels of the mitochondrial biogenesis regulator, $P g c 1 \alpha$. Consistently, we found that HC toxin increased OCR in cultured myotubes (Fig. 4), providing evidence for an enhanced oxidative capacity in the treated myotubes. Interestingly, several gene expression changes induced by $\mathrm{HC}$ toxin parallels those observed in exercise. Indeed, multiple human studies have shown that $L p l$ and Cs mRNA levels are upregulated in skeletal muscle after exercise (Siu et al. 2003, Vissing et al. 2005). Additionally, chronic exercise increases $C p t 1 b$ (Tunstall et al. 2002), Slc25a20 (Lammers et al. 2012) and

Published by Bioscientifica Ltd 

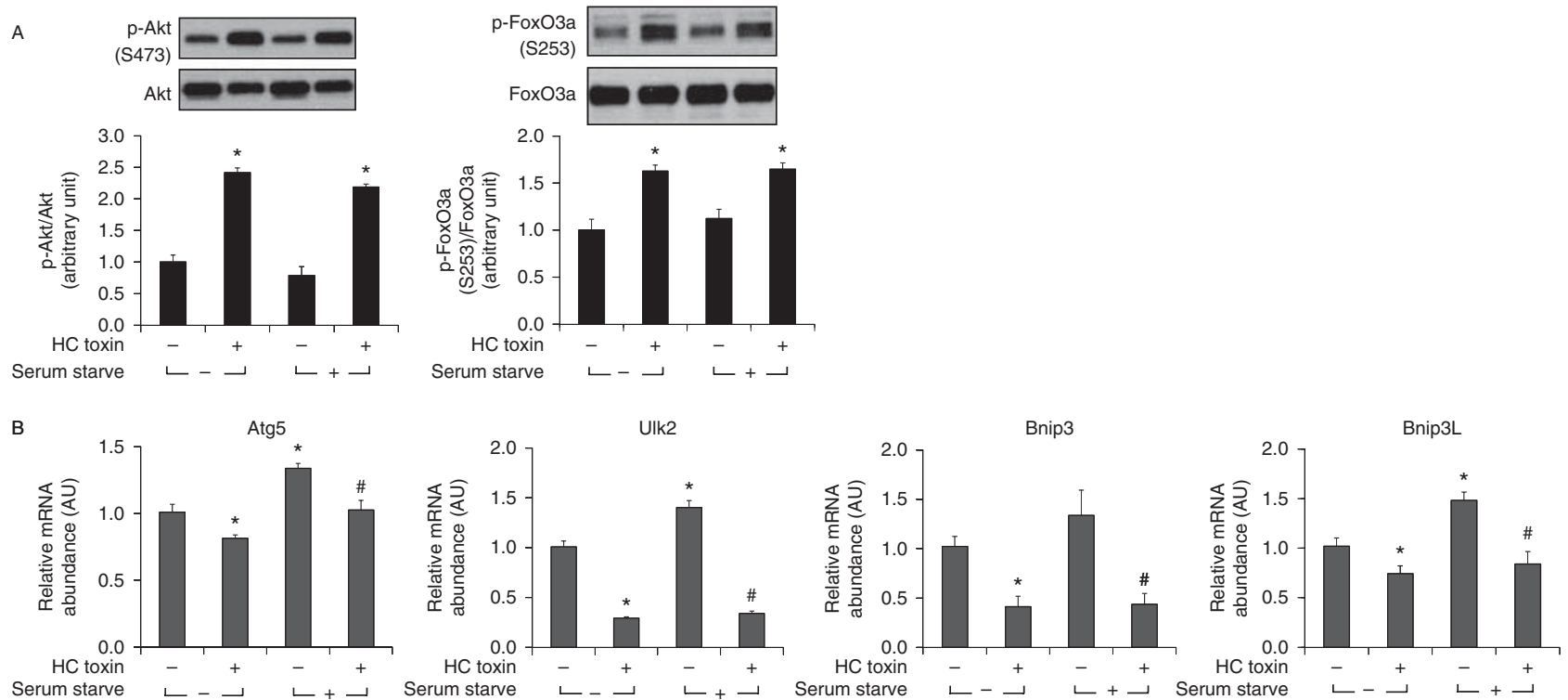

C
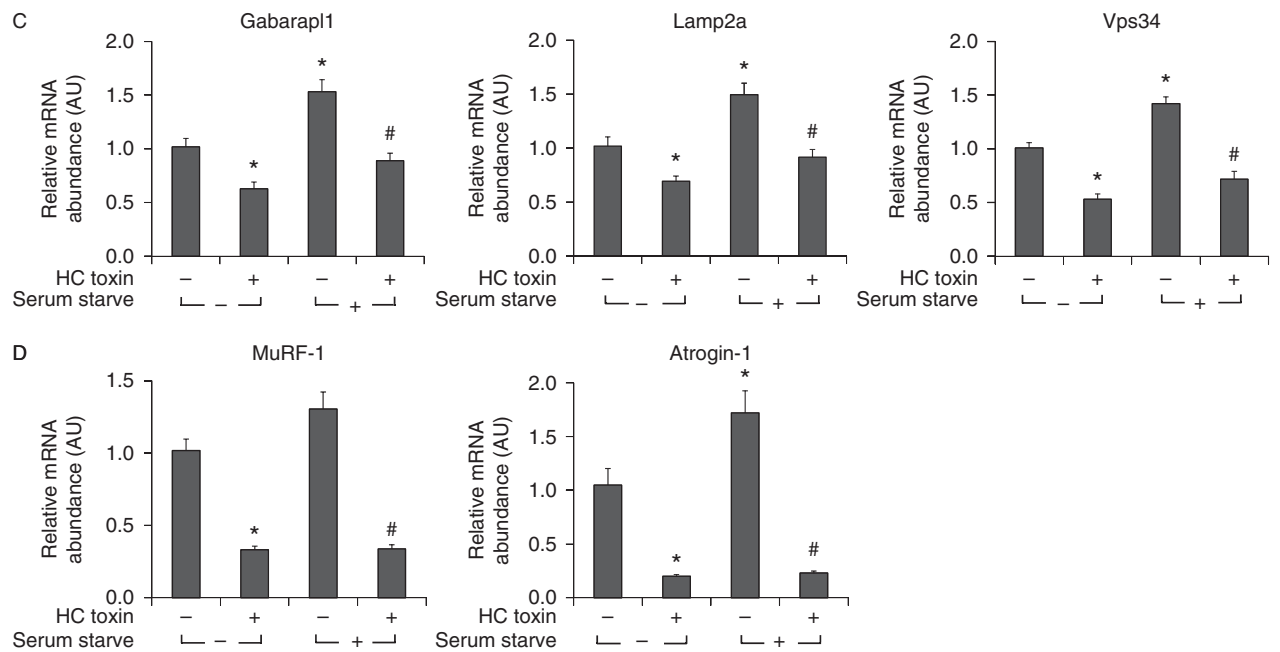

Figure 5

$\mathrm{HC}$ toxin suppresses the expression of atrophy-related genes during nutrient deprivation. (A) $\mathrm{C} 2 \mathrm{C} 12$ myotubes were incubated with $\mathrm{HC}$ toxin $(100 \mathrm{nM})$ for $48 \mathrm{~h}$ with or without serum-starvation for the last $6 \mathrm{~h}$ of treatment. Phosphorylation and protein levels of Akt and FoxO3a were assessed by western blot. Representative blots and quantification are presented. ( $\mathrm{B}, \mathrm{C}$, and $\mathrm{D}) \mathrm{C} 2 \mathrm{C} 12$ myotubes were incubated with $\mathrm{HC}$ toxin $(100 \mathrm{nM})$ for $48 \mathrm{~h}$ with or without serum starvation for the final $8 \mathrm{~h}$. Expression of ( $B$ and $C$ ) autophagy and (D) ubiquitin-proteasome related genes were assessed by $q P C R$. Bars indicate mean \pm s. E.M. ${ }^{\star} P<0.05$ vs the control group; ${ }^{\#} P<0.05$ vs the serum starvation group; $n=6$.
Pgc1a (Baar et al. 2002). Thus, the pharmacological effects of $\mathrm{HC}$ toxin are sufficient to enhance gene expression and metabolism induced by exercise.

The Akt-FoxO axis regulates the transcription of genes involved in autophagy and the ubiquitin-proteasomal pathway (collectively termed atrogenes) (Zhao et al. 2007); these genes are associated with muscle atrophy/wasting during prolonged periods of inactivity and in disease states such as diabetes and cancer cachexia (Glover \& Phillips 2010). Akt phosphorylates and induces the cytoplasmic localisation of FoxO3a, which suppresses the expression of atrogenes. Given that Akt is activated in response to treatment with $\mathrm{HC}$ toxin, we asked whether this activation is sufficient to suppress the expression of atrogenes. We show that HC toxin-induced Akt activation causes FoxO3a phosphorylation and an associated suppression of atrogene expression (Fig. 5). This suppression was retained under serum-starved conditions, which is routinely used to induce atrophy in myotubes. Our findings corroborate those of several studies that have demonstrated 
the suppression of various atrogenes following HDAC inhibition. The inhibition of class I and II HDACs by the pan-HDAC inhibitor, TSA, suppresses the induction of MuRF-1 and atrogin-1 by dexamethasone or nutrient deprivation in C2C12 myotubes (Bricceno et al. 2012, Beharry et al. 2014). Similarly, the class I HDAC inhibitor, MGCD0103, suppresses the expression of numerous autophagy genes (Vps34, Gabarap) and several Atg proteins in CLL cells (El-Khoury et al. 2014). Additionally, fastinginduced autophagy gene expression (Atg5 and Gabarap1) is attenuated in the skeletal muscle of HDAC1/2 knockout mice (Moresi et al. 2012). Overall, our results demonstrate that HC toxin is able to suppress atrogene expression, which is associated with reduced skeletal muscle atrophy.

While Akt activation in skeletal muscle exerts multiple beneficial effects as discussed earlier, activation of Akt in the liver leads to many undesired effects. This was previously demonstrated in a study in which expression of constitutively active Akt in mouse liver resulted in elevated serum cholesterol and triglyceride levels, as well as hepatic triglyceride accumulation and hepatomegaly (Ono et al. 2003). Thus, we evaluated whether HC toxin could induce activation of Akt in multiple liver cell lines. Our data provided evidence that HC toxin treatment did not activate IRS1-Akt signalling in HepG2, H4IIE, Huh7 and Huh6 cells. (Supplementary Figure 1, see section on supplementary data given at the end of this article). This suggested that HC toxin-induced Akt activation may be limited to terminally differentiated myotubes and not actively proliferating hepatoma cells.

Studies on exercise-induced cellular signalling and gene signatures have shed light on the potential mechanisms that mediate the medical benefits of exercise in obesity, type 2 diabetes and muscle atrophy (Richter \& Ruderman 2009, Glover \& Phillips 2010, Egan \& Zierath 2013). Here, we provide evidence that HC toxin (an HDAC inhibitor) induces cellular signalling and metabolic modifications that are associated with exercise adaptations. Long-term treatment of HC toxin in cultured myotubes induced IRS1-Akt signalling and affected the expression of metabolic genes involved in substrate utilisation and genes linked with muscle atrophy. Our findings suggest that HDAC inhibitors may have therapeutic potential in recapitulating the physiological adaptations of exercise through skeletal muscle metabolic reprogramming. Given that HDAC inhibitors are widely pursued cancer therapeutics, the field of diabetes research may leverage on the wealth of information and compound libraries from oncological studies.

\section{Supplementary data}

This is linked to the online version of the paper at http://dx.doi.org/10.1530/ JME-15-0140.

Declaration of interest

The authors declare that there is no conflict of interest that could be perceived as prejudicing the impartiality of the research reported.

\section{Funding}

This work was supported by grants from the National Medical Research Council (NMRC), Singapore (NMRC/BNIG/2013/2013) and the Singapore Ministry of Education Academic Research Fund (T1-2011 Sep-05 and T1-2014 Apr-05) awarded to Y C L.

\section{References}

Abdul-Ghani MA \& DeFronzo RA 2010 Pathogenesis of insulin resistance in skeletal muscle. Journal of Biomedicine \& Biotechnology 2010 article 476279. (doi:10.1155/2010/476279)

Baar K, Wende AR, Jones TE, Marison M, Nolte LA, Chen M, Kelly DP \& Holloszy JO 2002 Adaptations of skeletal muscle to exercise: rapid increase in the transcriptional coactivator PGC-1. FASEB Journal 16 1879-1886. (doi:10.1096/fj.02-0367com)

Barnes BR, Long YC, Steiler TL, Leng Y, Galuska D, Wojtaszewski JF, Andersson L \& Zierath JR 2005 Changes in exercise-induced gene expression in 5'-AMP-activated protein kinase $\gamma 3$-null and $\gamma 3$ R225Q transgenic mice. Diabetes 54 3484-3489. (doi:10.2337/diabetes.54.12. 3484)

Beharry AW, Sandesara PB, Roberts BM, Ferreira LF, Senf SM \& Judge AR 2014 HDAC1 activates FoxO and is both sufficient and required for skeletal muscle atrophy. Journal of Cell Science 127 1441-1453. (doi:10.1242/jcs.136390)

Bodine SC, Stitt TN, Gonzalez M, Kline WO, Stover GL, Bauerlein R, Zlotchenko E, Scrimgeour A, Lawrence JC, Glass DJ et al. 2001 $\mathrm{Akt} / \mathrm{mTOR}$ pathway is a crucial regulator of skeletal muscle hypertrophy and can prevent muscle atrophy in vivo. Nature Cell Biology 3 1014-1019. (doi:10.1038/ncb1101-1014)

Bricceno KV, Sampognaro PJ, Van Meerbeke JP, Sumner CJ, Fischbeck KH \& Burnett BG 2012 Histone deacetylase inhibition suppresses myogenindependent atrogene activation in spinal muscular atrophy mice. Human Molecular Genetics 21 4448-4459. (doi:10.1093/hmg/dds286)

Brosch G, Ransom R, Lechner T, Walton JD \& Loidl P 1995 Inhibition of maize histone deacetylases by HC toxin, the host-selective toxin of Cochliobolus carbonum. Plant Cell 7 1941-1950. (doi:10.1105/tpc.7. 11.1941)

De Ruijter A, Van Gennip A, Caron H, Kemp S \& van Kuilenburg AB 2003 Histone deacetylases (HDACs): characterization of the classical HDAC family. Biochemical Journal 370 737-749. (doi:10.1042/bj20021321)

De Sarno P, Li X \& Jope RS 2002 Regulation of Akt and glycogen synthase kinase-3 $\beta$ phosphorylation by sodium valproate and lithium. Neuropharmacology 43 1158-1164. (doi:10.1016/S0028-3908(02)00215-0)

Deshmukh A, Coffey VG, Zhong Z, Chibalin AV, Hawley JA \& Zierath JR 2006 Exercise-induced phosphorylation of the novel Akt substrates AS160 and filamin A in human skeletal muscle. Diabetes 55 1776-1782. (doi:10.2337/db05-1419)

Drummond MJ, Fry CS, Glynn EL, Dreyer HC, Dhanani S, Timmerman KL Volpi E \& Rasmussen BB 2009 Rapamycin administration in humans blocks the contraction-induced increase in skeletal muscle protein synthesis. Journal of Physiology 587 1535-1546. (doi:10.1113/jphysiol. 2008.163816)

Published by Bioscientifica Ltd. 
Egan B \& Zierath JR 2013 Exercise metabolism and the molecular regulation of skeletal muscle adaptation. Cell Metabolism 17 162-184 (doi:10.1016/j.cmet.2012.12.012)

El-Khoury V, Pierson S, Szwarcbart E, Brons NH, Roland O, Cherrier-De Wilde S, Plawny L, Van Dyck E \& Berchem G 2014 Disruption of autophagy by the histone deacetylase inhibitor MGCD0103 and its therapeutic implication in B-cell chronic lymphocytic leukemia. Leukemia 28 1636-1646. (doi:10.1038/leu.2014.19)

Finck BN \& Kelly DP 2006 PGC-1 coactivators: inducible regulators of energy metabolism in health and disease. Journal of Clinical Investigation 116 615-622. (doi:10.1172/JCI27794)

Gao Z, Yin J, Zhang J, Ward RE, Martin RJ, Lefevre M, Cefalu WT \& Ye J 2009 Butyrate improves insulin sensitivity and increases energy expenditure in mice. Diabetes 58 1509-1517. (doi:10.2337/db08-1637)

Glover EI \& Phillips SM 2010 Resistance exercise and appropriate nutrition to counteract muscle wasting and promote muscle hypertrophy. Current Opinion in Clinical Nutrition and Metabolic Care 13 630-634. (doi:10.1097/MCO.0b013e32833f1ae5)

Hajduch E, Alessi DR, Hemmings BA \& Hundal HS 1998 Constitutive activation of protein kinase $\mathrm{B} \alpha$ by membrane targeting promotes glucose and system A amino acid transport, protein synthesis, and inactivation of glycogen synthase kinase 3 in L6 muscle cells. Diabetes 47 1006-1013. (doi:10.2337/diabetes.47.7.1006)

Hawley JA 2004 Exercise as a therapeutic intervention for the prevention and treatment of insulin resistance. Diabetes/Metabolism Research and Reviews 20 383-393. (doi:10.1002/dmrr.505)

Henriksen EJ 2002 Invited Review: Effects of acute exercise and exercise training on insulin resistance. Journal of Applied Physiology 93 788-796. (doi:10.1152/japplphysiol.01219.2001)

Hildmann C, Wegener D, Riester D, Hempel R, Schober A, Merana J, Giurato L, Guccione S, Nielsen TK, Ficner R et al. 2006 Substrate and inhibitor specificity of class 1 and class 2 histone deacetylases. Journal of Biotechnology 124 258-270. (doi:10.1016/j.jbiotec.2006.01.030)

Izumiya Y, Hopkins T, Morris C, Sato K, Zeng L, Viereck J, Hamilton JA, Ouchi N, LeBrasseur NK \& Walsh K 2008 Fast/Glycolytic muscle fiber growth reduces fat mass and improves metabolic parameters in obese mice. Cell Metabolism 7 159-172. (doi:10.1016/j.cmet.2007.11.003)

Jessen N, Pold R, Buhl ES, Jensen LS, Schmitz O \& Lund S 2003 Effects of AICAR and exercise on insulin-stimulated glucose uptake, signaling, and GLUT-4 content in rat muscles. Journal of Applied Physiology 94 1373-1379. (doi:10.1152/japplphysiol.00250.2002)

Kovacs P, Hanson RL, Lee YH, Yang X, Kobes S, Permana PA, Bogardus C \& Baier LJ 2003 The role of insulin receptor substrate-1 gene (IRS1) in type 2 diabetes in Pima Indians. Diabetes 52 3005-3009. (doi:10.2337/ diabetes.52.12.3005)

Kubica N, Bolster DR, Farrell PA, Kimball SR \& Jefferson LS 2005 Resistance exercise increases muscle protein synthesis and translation of eukaryotic initiation factor 2Bepsilon mRNA in a mammalian target of rapamycin-dependent manner. Journal of Biological Chemistry $\mathbf{2 8 0}$ 7570-7580. (doi:10.1074/jbc.M413732200)

Lammers G, Poelkens F, van Duijnhoven NT, Pardoel EM, Hoenderop JG, Thijssen DH \& Hopman MT 2012 Expression of genes involved in fatty acid transport and insulin signaling is altered by physical inactivity and exercise training in human skeletal muscle. American Journal of Physiology. Endocrinology and Metabolism 303 1245-1251. (doi:10.1152/ ajpendo.00356.2012)

Long YC \& Zierath JR 2006 AMP-activated protein kinase signaling in metabolic regulation. Journal of Clinical Investigation 1161776. (doi:10.1172/JCI29044)

Mahoney DJ, Parise G, Melov S, Safdar A \& Tarnopolsky MA 2005 Analysis of global mRNA expression in human skeletal muscle during recovery from endurance exercise. FASEB Journal 19 1498-1500. (doi:10.1096/fj. 04-3149fje)

Manning BD \& Cantley LC 2007 AKT/PKB signaling: navigating downstream. Cell 129 1261-1274. (doi:10.1016/j.cell.2007.06.009)
Moresi V, Carrer M, Grueter CE, Rifki OF, Shelton JM, Richardson JA \& Olson EN 2012 Histone deacetylases 1 and 2 regulate autophagy flux and skeletal muscle homeostasis in mice. PNAS 109 1649-1654. (doi:10.1073/pnas.1121159109)

Mottamal M, Zheng S, Huang TL \& Wang G 2015 Histone deacetylase inhibitors in clinical studies as templates for new anticancer agents. Molecules 20 3898-3941. (doi:10.3390/molecules20033898)

Mu J, Brozinick JT Jr, Valladares O, Bucan M \& Birnbaum MJ 2001 A role for AMP-activated protein kinase in contraction-and hypoxia-regulated glucose transport in skeletal muscle. Molecular Cell 7 1085-1094. (doi:10.1016/S1097-2765(01)00251-9)

Ono H, Shimano H, Katagiri H, Yahagi N, Sakoda H, Onishi Y, Anai M, Ogihara T, Fujishiro M, Viana AY et al. 2003 Hepatic Akt activation induces marked hypoglycemia, hepatomegaly, and hypertriglyceridemia with sterol regulatory element binding protein involvement. Diabetes 52 2905-2913. (doi:10.2337/diabetes.52.12.2905)

Osorio-Fuentealba C, Contreras-Ferrat AE, Altamirano F, Espinosa A, Li Q, Niu W, Lavandero S, Klip A \& Jaimovich E 2013 Electrical stimuli release ATP to increase GLUT4 translocation and glucose uptake via PI3K $\gamma$-AktAS160 in skeletal muscle cells. Diabetes 62 1519-1526. (doi:10.2337/ db12-1066)

Pallafacchina G, Calabria E, Serrano AL, Kalhovde JM \& Schiaffino S 2002 A protein kinase B-dependent and rapamycin-sensitive pathway controls skeletal muscle growth but not fiber type specification. PNAS 99 9213-9218. (doi:10.1073/pnas.142166599)

Pold R, Jensen LS, Jessen N, Buhl ES, Schmitz O, Flyvbjerg A, Fujii N, Goodyear LJ, Gotfredsen CF, Brand CL et al. 2005 Long-term AICAR administration and exercise prevents diabetes in ZDF rats. Diabetes 54 928-934. (doi:10.2337/diabetes.54.4.928)

Raichur S, Teh SH, Ohwaki K, Gaur V, Long YC, Hargreaves M, McGee SL \& Kusunoki J 2012 Histone deacetylase 5 regulates glucose uptake and insulin action in muscle cells. Journal of Molecular Endocrinology 49 203-211. (doi:10.1530/JME-12-0095)

Reed SA, Sandesara PB, Senf SM \& Judge AR 2012 Inhibition of FoxO transcriptional activity prevents muscle fiber atrophy during cachexia and induces hypertrophy. FASEB Journal 26 987-1000. (doi:10.1096/ fj.11-189977)

Richter E \& Ruderman N 2009 AMPK and the biochemistry of exercise: implications for human health and disease. Biochemical Journal 418 261-275. (doi:10.1042/BJ20082055)

Sakamoto K, Aschenbach WG, Hirshman MF \& Goodyear LJ 2003 Akt signaling in skeletal muscle: regulation by exercise and passive stretch. American Journal of Physiology. Endocrinology and Metabolism 285 1081-1088. (doi:10.1152/ajpendo.00228.2003)

Sandri M, Sandri C, Gilbert A, Skurk C, Calabria E, Picard A, Walsh K, Schiaffino S, Lecker SH \& Goldberg AL 2004 Foxo transcription factors induce the atrophy-related ubiquitin ligase atrogin-1 and cause skeletal muscle atrophy. Cell 117 399-412. (doi:10.1016/S00928674(04)00400-3)

Shah OJ \& Hunter T 2006 Turnover of the active fraction of IRS1 involves raptor-mTOR-and S6K1-dependent serine phosphorylation in cell culture models of tuberous sclerosis. Molecular and Cellular Biology 26 6425-6434. (doi:10.1128/MCB.01254-05)

Siu PM, Donley DA, Bryner RW \& Alway SE 2003 Citrate synthase expression and enzyme activity after endurance training in cardiac and skeletal muscles. Journal of Applied Physiology 94 555-560. (doi:10.1152/ japplphysiol.00821.2002)

Sugden MC \& Holness MJ 2003 Recent advances in mechanisms regulating glucose oxidation at the level of the pyruvate dehydrogenase complex by PDKs. American Journal of Physiology. Endocrinology and Metabolism 284 855-862. (doi:10.1152/ajpendo.00526.2002)

Taniguchi CM, Emanuelli B \& Kahn CR 2006 Critical nodes in signalling pathways: insights into insulin action. Nature Reviews. Molecular Cell Biology 7 85-96. (doi:10.1038/nrm1837)

Tunstall RJ, Mehan KA, Wadley GD, Collier GR, Bonen A, Hargreaves M \& Cameron-Smith D 2002 Exercise training increases lipid metabolism

Published by Bioscientifica Ltd. 
gene expression in human skeletal muscle. American Journal of Physiology. Endocrinology and Metabolism 283 66-72. (doi:10.1152/ ajpendo.00475.2001)

Vissing K, Andersen JL \& Schjerling P 2005 Are exercise-induced genes induced by exercise? FASEB Journal 19 94-96. (doi:10.1096/fj.04-2084fje)

Weigert C, Kron M, Kalbacher H, Pohl AK, Runge H, Haring HU, Schleicher E \& Lehmann R 2008 Interplay and effects of temporal changes in the phosphorylation state of serine-302, -307, and -318 of insulin receptor substrate-1 on insulin action in skeletal muscle cells. Molecular Endocrinology 22 2729-2740. (doi:10.1210/me.2008-0102)

Wojtaszewski JF, Hansen BF, Ursø B \& Richter EA 1996 Wortmannin inhibits both insulin-and contraction-stimulated glucose uptake and transport in rat skeletal muscle. Journal of Applied Physiology $\mathbf{8 1}$ 1501-1509.

Yamauchi T, Tobe K, Tamemoto H, Ueki K, Kaburagi Y, Yamamoto-Honda R, Takahashi Y, Yoshizawa F, Aizawa S, Akanuma Y et al. 1996 Insulin signalling and insulin actions in the muscles and livers of insulin-resistant, insulin receptor substrate 1-deficient mice. Molecular and Cellular Biology 16 3074-3084.

Zhao J, Brault JJ, Schild A, Cao P, Sandri M, Schiaffino S, Lecker SH \& Goldberg AL 2007 FoxO3 coordinately activates protein degradation by the autophagic/lysosomal and proteasomal pathways in atrophying muscle cells. Cell Metabolism 6 472-483. (doi:10.1016/ j.cmet.2007.11.004)

Received in final form 10 September 2015

Accepted 14 September 2015

Accepted Preprint published online 15 September 2015
Published by Bioscientifica Ltd. 